\title{
Esofagite Eosinofílica: AtualizaÇÃo de Conceitos e Manejo Clínico
}

\section{Autores}

Élio C. Castro Filho

A Esofagite Eosinofílica (EoE) é uma doença inflamatória crônica do esôfago, de natureza imunológica e mediada por antígenos alimentares. Clinicamente se manifesta por sintomas de disfunção esofagiana e histologicamente por inflamaçáo com predomínio de eosinófilos ${ }^{1,2}$. Embora seja uma doença de reconhecimento relativamente recente, adquiriu grande relevância clínica nas últimas 2 décadas, despertando o interesse da comunidade científica e gerando atualização de conceitos e abordagem terapêutica.

Com base em estudos do hemisfério norte, a prevalência estimada em crianças fica em torno de 43 casos por 100 mil habitantes, enquanto em adultos varia entre $40 \mathrm{e}$ 56 casos por 100 mil habitantes, tendo sido observado um aumento significativo tanto da incidência quanto da prevalência dessa doença1. É incerto dizer se há um aumento real de casos ou se há mais diagnósticos devido a uma maior atençáo em torno da doença.
Embora os casos possam ocorrer em qualquer idade, a grande maioria se concentra na faixa etária pediátrica, em adolescente e adultos jovens (com menos de 50 anos), tendo forte associação com outros quadros alérgicos, em especial rinite, asma e eczema atópico. Hoje em dia pode ser considerada a doença crônica mais comum do esôfago depois da Doença do Refluxo Gastroesofágico (DRGE) e a maior causa de disfagia e impactação alimentar em crianças e adultos jovens ${ }^{1}$. Há um notório predomínio no sexo masculino, sendo este considerado um fator de alto risco para a doença ${ }^{3}$.

Sua importância clínica se deve ao fato de que, além da incidência crescente reportada na literatura, precisa ser reconhecida e tratada adequadamente numa fase precoce, caso contrário tem grande potencial de evoluir para fibrose e estenose de esôfago em pacientes jovens $s^{4}$. O grande esforço do médico deve ser garantir a adesáo do paciente ao esquema de tratamento escolhido. Isso porque, à luz do conhecimento atual, a terapia de manutenção está indicada para toda a vida $^{1,2,5}$. 


\section{BREVE HISTÓRICO: DOS \\ Primeiros Conceitos à ETIOPATOGENia DA DoENÇA}

A presença de inflamação com predomínio de eosinófilos no esôfago foi inicialmente descrita como um marcador histológico da doença do refluxo gastroesofágico (DRGE) no início dos anos $1980^{6}$. Esse entendimento permaneceu inalterado por cerca de uma década, quando foram publicados estudos sugerindo que esta seria uma entidade clinicopatológica própria $^{7}$ com evidências de que poderia ser deflagrada por antígenos alimentares ${ }^{8}$.

O estudo pioneiro que observou a relação entre eosinofilia esofagiana e o consumo de determinados alimentos foi conduzido em crianças que tinham diagnóstico prévio de DRGE, mas refratárias ao tratamento com Inibidores da Bomba de Prótons (IBP) e até mesmo à cirurgia de fundoplicatura de Nissen ${ }^{8}$. Houve melhora dos sintomas e da eosinofilia esofagiana após implementação de uma dieta elementar à base de aminoácidos. Em pouco tempo esse mesmo padrão foi observado em adultos jovens, sugerindo tratar-se de uma doença com um curso próprio, distinta da DRGE.

Apesar do crescente número de publicaçôes sobre o assunto desde então, apenas em 2007 veio o primeiro consenso de especialistas, definindo os critérios diagnósticos da doença ${ }^{9}$. Seria necessária uma contagem superior a 15 eosinófilos por campo de grande aumento na mucosa do esôfago (ausente no restante do tubo digestivo), excluindo-se a presença de DRGE através de uma pHmetria de 24 horas normal ou refratariedade a um tratamento longo IBPs em dose dobrada. Convencionou-se, portanto, que DRGE e EoE seriam doenças auto excludentes.

Estabeleceram-se também os corticoides tópicos (fluticasona e budesonida) como medicaçôes eficazes no controle dos sintomas e redução da inflamaçáo. Sendo uma alternativa de tratamento à dieta restritiva, considerada de difícil adesáo pelos pacientes ${ }^{10}$.

Um novo consenso de especialistas foi publicado em $2011^{11}$, no qual se enfatizava a natureza imunológica da Esofagite Eosinofílica e a participação dos antígenos alimentares na sua etiopatogenia. Porém, a grande novidade foi chamar atenção para um subgrupo de pacientes que apresentavam pHmetria de 24 horas normal e não tinham qualquer outra evidência de DRGE, mas apresentavam contagem de eosinófilos no epitélio do esôfago $\geq 15 / \mathrm{cga}$, com resposta à terapia com IBP. Convenciou-se classificálos como portadores de Eosinofilia Esofagiana responsiva a $I B P$, que poderiam representar tanto uma nova entidade nosológica quanto um subgrupo de pacientes portadores de DRGE com pHmetria normal ${ }^{11}$.

Graças à descoberta do perfil genético associado à Esofagite Eosinofílica ${ }^{12}$, estudo posteriores concluíram que os pacientes com 
diagnóstico de Eosinofilia Esofagiana responsiva a IBP apresentam um perfil semelhante, com o mesmo padrão de expressáo genética, o que significa que podem representar a mesma doença com uma apresentação fenotípica diferente ${ }^{13}$.

Aliado a isto, recentemente também se demonstrou que os inibidores de bomba de prótons (IBP) exercem um ação anti-inflamatória diretamente na mucosa do esôfago. Estas drogas teriam efeito inibitório tanto em determinadas células inflamatórias (Linfócitos Th2), quanto na produção de citocinas inflamatórias pelas células epiteliais (IL-13, IL-4 e IL-5), reduzindo a expressão da eotaxina ${ }^{314-16}$, que é a principal responsável pela quimiotaxia dos eosinófilos para o epitélio esofágico. Esse efeito do IBP seria independente da inibição da secreção ácida.

Essa descoberta representou uma importante mudança de paradigma sobre o papel dessas drogas, sendo publicado um novo consenso de especialistas em $2018^{2}$, posteriormente reforçado num consenso conjunto da AGA com a Sociedade de Alergia e Imunologia Americana em 202017, considerando o IBP como uma opção terapêutica de primeira linha no tratamento da Esofagite Eosinofílica.

Outro conceito que se incorporou é que DRGE e EoE podem coexistir e ter efeito sinérgico. A exposição ácida prolongada no esôfago distal provoca o alargamento dos espaços intercelulares ${ }^{18,19}$ e isso aumentaria a exposição dos antígenos alimentares à camada subepitelial, gerando maior ativação dos linfócitos Th2, com produçáo das interleucinas IL-13, IL-4 e IL-5 e expressão do sinalizador celular STAT6, que promoveria a produção da Eotaxina-3 (responsável pela quimiotaxia dos eosinófilos) ${ }^{16}$. O papel do IBP nesse cenário seria importante por interromper o mecanismo de ambas as doenças ${ }^{2,20}$.

Possivelmente, há diferentes fenótipos da doença com respostas distintas ao IBP, devendo haver um grupo em que a terapia com corticoides tópicos tenha maior benefício e o mesmo pode ser dito em relação à dieta restritiva ${ }^{2}$. O conhecimento desses padróes fenotípicos não está definido e deve ser o próximo desafio no estudo da doença, o que permitirá individualizar a indicação do melhor tratamento ${ }^{17}$.

\section{Sintomas E Evolução Clínica}

O quadro sugestivo da doença ocorre em crianças e adultos jovens que apresentam sintomas recorrentes de disfunção esofagiana, especialmente se tiverem história de outras manifestaçóes alérgicas, como rinite, asma e eczema atópico, e forem do sexo masculino, que é considerado um fator de alto risco para a doença ${ }^{1,3}$.

A alergia ambiental cruzada é tão importante, que há dados abundantes na literatura sugerindo o grande impacto dos ae- 
roalérgenos em deflagrar os sintomas e exacerbar a atividade da $\mathrm{EoE}^{17,21}$. Por isso, pacientes com suspeita clínica dessa condição devem ser encaminhados para acompanhamento conjunto com o alergista, para que sejam conduzidos testes para alérgenos ambientais e realizada a adequada dessensibilização.

A disfunção esofagiana ocorre devido ao espessamento inflamatório da parede do órgão, o que compromete a sua motilidade e a condução adequada do bolo alimentar. Com a evolução da doença, advêm fibrose e estenose progressivas do órgão ${ }^{4}$.

De acordo com a idade do paciente, a manifestação dos sintomas pode variar, sendo mais inespecíficos em lactentes e pré-escolares e mais típicos (impactação e disfagia) em adolescente maiores de 12 anos e em adultos jovens entre 20 e 50 anos.

Os principais sintomas por faixa etária se encontram no Quadro 1 abaixo1:

\begin{tabular}{|l|l|}
\hline \multicolumn{2}{|c|}{$\begin{array}{c}\text { Quadro 1: sintomas da Esofagite } \\
\text { Eosinofílica por faixa etária }\end{array}$} \\
\hline $\begin{array}{c}\text { Crianças (Lactentes e } \\
\text { pré-escolares) }\end{array}$ & \multicolumn{1}{c|}{$\begin{array}{c}\text { Adolescentes (> 12 anos) } \\
\text { e adultos jovens (20 - } \\
\mathbf{5 0} \text { anos) }\end{array}$} \\
\hline - Sintomas de refluxo & $\begin{array}{l}\text { • Impactação alimentar } \\
\text { (33-54\%) }\end{array}$ \\
\hline - Vômitos & • Pirose \\
\hline - Dor abdominal & • Regurgitação \\
\hline - Recusa alimentar & • Desconforto retroesternal \\
\hline $\begin{array}{l}\text { - Dificuldade de } \\
\text { introdução ou } \\
\text { progressão alimentar }\end{array}$ & $\begin{array}{l}\text { • Dor no peito induzida pelo } \\
\text { exercício }\end{array}$ \\
\hline
\end{tabular}

Estudos demonstraram que o processo inflamatório nessa doença pode se estender profundamente pela parede do esôfago, havendo evidências de que pode chegar à camada muscular ${ }^{22,23}$. Dessa maneira, em longo prazo o estímulo fibrogênico poderia levar ao remodelamento do esôfago, com estreitamento progressivo do seu calibre e comprometimento cada vez maior da sua motilidade ${ }^{4}$. A doença teria uma primeira fase inflamatória que evoluiria progressivamente até uma fase fibroestenótica ${ }^{23}$.

Sintomas como disfagia e impactaçōes tanto podem ocorrer em decorrência do processo inflamatório quanto pela fibrose já estabelecida, não sendo bons indicadores do estágio da doença.

Modelos de sobrevida estimam que a cada ano de doença não diagnosticada, o risco de estenose aumenta 9\%4, e após 30 anos de evolução sem nenhum tratamento, mais de $80 \%$ dos pacientes terão estenose definitiva $^{24}$. Considerando que a doença pode ter início na infância, esse é um prognóstico bastante ruim e preocupante.

\section{Avaliação Diagnóstica: O Papel da Endoscopia Digestiva Alta (EDA)}

Diante da suspeita clínica de Esofagite Eosinofílica, o exame mais importante é a Endoscopia Digestiva Alta com biópsias do esôfago, considerado o padrão-ouro para o diagnóstico. Os achados endoscópicos não são específicos da doença, mas levantam 
fortemente a sua suspeita quando vistos em conjunto.

Atenção: Muitos pacientes com suspeita clínica de Esofagite Eosinofílica podem se apresentar com Endoscopia Digestiva Alta normal ou com mínimos achados inespecíficos. Mesmo assim, as biópsias da mucosa do esôfago estão indicadas. Em crianças, a EDA normal pode ocorrer em até $32 \%{ }^{25}$.

Na Tabela 1 estão os achados endoscópicos mais comuns e suas respectivas frequências:

Tabela 1: Achados endoscópicos sugestivos de Esofagite Eosinofílica

\begin{tabular}{l|l}
\hline Achados & Frequência \\
\hline $\begin{array}{l}\text { Sulcos verticais (ou estrias } \\
\text { longitudinais) }\end{array}$ & $80 \%$ \\
\hline Anéis/traqueização & $64 \%$ \\
\hline Exsudatos/placas brancacentas & $16 \%$ \\
\hline Estenoses/ esôfago de fino calibre & $12 \%$ \\
\hline
\end{tabular}

Normalmente, o edema, os sulcos verticais e os exsudatos se associam à fase inflamatória da doença. Já os anéis e estenoses são sugestivos da fase fibroestenótica.

A classificação endoscópica E.R.E.F.S. (Endoscopic REFerence Scale) atribui uma pontuação a cada um desses achados, criando uma escala numérica que indica piora da doença conforme aumenta a soma dos valores $^{26}$. Apesar de ainda ser pouco difundida, essa escala já foi validada internacionalmente, tanto em crianças quanto em adultos, e permite uma avaliação endoscópica mais objetiva e padronizada, sendo estimulado o seu uso no acompanhamento da atividade inflamatória da $\mathrm{EoE}^{26,27}$.

Veja a classificação endoscópica EREFS no Quadro 2 abaixo:

\begin{tabular}{|c|c|c|c|c|}
\hline \multicolumn{5}{|c|}{ Quadro 2: Classificação endoscópica EREFS (Endoscopic Reference Scale)* } \\
\hline \multirow{2}{*}{ Achado Endoscópico } & \multicolumn{4}{|c|}{ Graus } \\
\hline & 0 & 1 & 2 & 3 \\
\hline Edema & $\begin{array}{l}\text { Ausente: } \\
\text { Padrão vascular } \\
\text { habitual }\end{array}$ & & & \\
\hline Rings (anéis) & $\begin{array}{l}\text { Ausentes: } \\
\text { Não há anéis }\end{array}$ & $\begin{array}{l}\text { Moderados: } \\
\text { Anéis bem evidentes } \\
\text { e demarcados }\end{array}$ & $\begin{array}{l}\text { Moderados: } \\
\text { Anéis bem evidentes } \\
\text { e demarcados }\end{array}$ & $\begin{array}{l}\text { Acentuados: } \\
\text { Anéis exuberantes, } \\
\text { "traqueização" }\end{array}$ \\
\hline $\begin{array}{l}\text { Exsudates } \\
\text { (exsudatos ou placas } \\
\text { brancacentas) }\end{array}$ & $\begin{array}{l}\text { Ausentes: } \\
\text { Não há exsudatos }\end{array}$ & $\begin{array}{l}\text { Moderados: } \\
\text { Ocupam > 10\% da } \\
\text { superfície do esôfago }\end{array}$ & $\begin{array}{l}\text { Moderados: } \\
\text { Ocupam > 10\% da } \\
\text { superfície do esôfago }\end{array}$ & \\
\hline $\begin{array}{l}\text { Furrows (sulcos } \\
\text { verticais) }\end{array}$ & $\begin{array}{l}\text { Ausentes: } \\
\text { Não há linhas }\end{array}$ & $\begin{array}{l}\text { Acentuadas: } \\
\text { Linhas bem } \\
\text { evidentes, profundas }\end{array}$ & $\begin{array}{l}\text { Acentuadas: } \\
\text { Linhas bem } \\
\text { evidentes, profundas }\end{array}$ & \\
\hline $\begin{array}{l}\text { Strictures } \\
\text { (estenoses) }\end{array}$ & $\begin{array}{l}\text { Ausentes: } \\
\text { Não há estenoses }\end{array}$ & & & \\
\hline
\end{tabular}

*A classificação final é obtida pela somatória dos valores em cada categoria. 
Em relação às biópsias do esôfago, pelo menos 6 fragmentos devem ser obtidos no total, incluindo terço proximal/médio e terço distal, direcionando-se a pinça para áreas de anormalidades na mucosa1. Em crianças são recomendadas também biópsias gástricas e duodenais para afastar gastroenterite eosinofílica. Em adultos, as biópsias de estômago e duodeno não são recomendadas rotineiramente, apenas se houver indicação clínica ou achados endoscópicos que justifiquem.

As Figuras 1 e 2 abaixo apresentam imagens endoscópicas com achados sugestivos da Esofagite Eosinofílica:
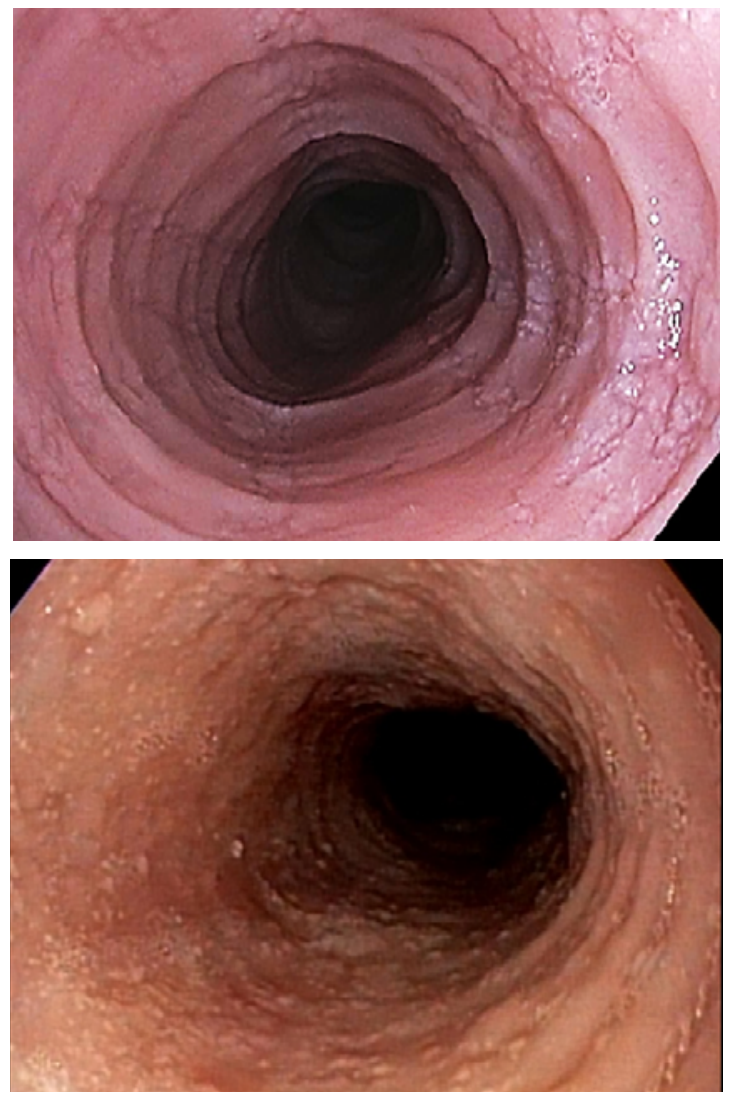

Figura 1: achados endoscópicos da Esofagite Eosinofilica: edema, estrias longitudinais, exsudatos e anéis.

Figura 2: achados endoscópicos da Esofagite Eosinofilica: edema, exsudatos e anéis.

\section{Análise Histopatológica da Mucosa}

A análise histopatológica convencional com uso da coloração Hematoxilina-Eosina (HE) é suficiente para o diagnóstico, que se baseia na contagem de eosinófilos na camada epitelial do esôfago igual ou superior 15 por campo de grande aumento ${ }^{1,2}$.

Outros achados são valorizados como marcadores de inflamação ativa, são eles a hiperplasia da camada basal, alongamento papilar, exocitose de eosinófilos, microabscesso de eosinófilo e dilatação dos espaços intercelulares. A fibrose da lâmina própria também pode ser observada ${ }^{1}$.

Outras técnicas como imunoistoquímica, microscopia eletrônica e microscopia confocal são usadas apenas para o propósito de pesquisa.

Atualmente, há um esforço das sociedades internacionais de patologia para padronizar critérios histológicos de atividade de doença que permitam avaliar a intensidade da inflamação e resposta ao tratamento ${ }^{17}$. No momento atual, o parâmetro mais utilizado é a queda da contagem de eosinófilos abaixo de $15 /$ cga.

\section{Diagnóstico Diferencial}


Após a confirmação da suspeita clínica pelos achados endoscópicos e histopatológicos, recomenda-se afastar outras causas sistêmicas e locais que poderiam causar eosinofilia esofagiana ${ }^{1,2}$. Cabe ressaltar que muitas dessas outras causas são incomuns e tem um curso clínico bem distinto, porém o médico deve tê-las em mente quando investiga um paciente suspeito de Esofagite Eosinofílica.

Observe no Quadro 3 outras causas de eosinofilia esofagiana:

\section{Quadro 3: Outras causas de eosinofilia esofagiana ${ }^{1,2}$}

- Doença do Refluxo Gastroesofágico (DRGE)

- Reação de hipersensibilidade a medicamentos

- Acalásia

- Doença Celíaca

- Infecção (fúngica e viral)

- Gastroenterite eosinofílica

- Síndrome hipereosinofílica

- Colagenoses (Síndrome de Marfan tipo II)

- Condições dermatológicas com envolvimento do esôfago (ex.: pênfigo)

- Vasculites e doenças autoimunes

- Doença de Crohn acometendo o esôfago

- Ingestão de agentes corrosivos

- Doença Enxerto-versus-hospedeiro

Outras técnicas não invasivas e minimamente invasivas

É bastante favorável a busca por técnicas não invasivas para monitorizar a inflamação e a contagem de eosinófilos no esôfago, evitando-se múltiplas endoscopias digestivas ao longo do tratamento. Entretanto, diversos biomarcadores foram estudados e nenhum deles mostrou boa correlação com a análise histopatológica ${ }^{1}$.

Entre os dispositivos minimamente invasivos, mostraram-se promissores aqueles desenvolvidos em forma de cápsulas feitas para deglutição, como a Cytosponge ${ }^{\circledast}$ (Medtronic, Minneapolis, Minn). Trata-se de uma pequena esponja compactada dentro de uma cápsula gelatinosa e presa a uma fina corda. $\mathrm{O}$ paciente deglute esta cápsula, que se desfaz em contato com o pH ácido do estômago, expondo a esponja que está no seu interior. A corda é então puxada e a esponja passa pelo esôfago coletando células superficiais. Este dispositivo foi desenvolvido inicialmente para avaliação do epitélio no Esôfago de Barrett e recentemente passou a ser avaliado no contexto da $\mathrm{EoE}^{28}$.

Resultados preliminares com esses dispositivos se mostraram bastante promissores, com uma eficácia de 83\% em identificar indivíduos em atividade inflamatória no esôfago ( $\geq 15$ eo/cga) 28 e estão atualmente sendo avaliados em estudos de larga escala para definir seu valor prognóstico na monitorização da $\mathrm{EoE}^{5}$. A Cytosponge ${ }^{\circledast}$ não está disponível no Brasil.

\section{AVAliaÇáo do REMODELAMENTO ESOFÁGICO}

Recentemente, um novo dispositivo chamado "endoscopic functional luminal imaging 
probe" ou endoFLIP ${ }^{\otimes}$ foi aprovado para uso nos EUA pelo FDA. Este equipamento se mostrou capaz de identificar a redução da complacência da parede do esôfago em adultos e crianças com Esofagite Eosinofílica.

Trata-se de uma técnica de platinometria por impedância, na qual se determina a resistência ou rigidez de um órgão tubular através da insuflação de um balão na sua luz. Esse balão contém eletrodos especiais, capazes de medir tanto o diâmetro quanto a pressão do órgão.

Durante uma endoscopia digestiva alta, um cateter conectado ao sistema endoFLIP ${ }^{\circledast}$ é passado através do canal de trabalho do endoscópio e posicionado na luz do esôfago. O balão na ponta do cateter é insuflado e o sistema faz a leitura da superfície por impedância, gerando informaçóes como cali- bre e formato do órgão, resistência e complacência do tecido.

Pode se tornar uma ferramenta importante tanto na avaliação da atividade inflamatória, quanto na identificação precoce do remodelamento e das estenoses. Dois estudos pediátricos preliminares correlacionaram positivamente a rigidez do tecido aferida pelo endoFLIP ${ }^{\circledR}$ ao grau de atividade inflamatória e à presença de fibrose/ estenose $^{29,30}$.

Apesar de promissor, tanto a sua eficácia diagnóstica quanto a prognóstica precisam ser mais bem avaliadas em estudos de validação, no contexto desta doença. Esse dispositivo não está disponível no Brasil.

A Figura 3 traz uma proposta de algoritmo diagnóstico para a Esofagite Eosinofílica.

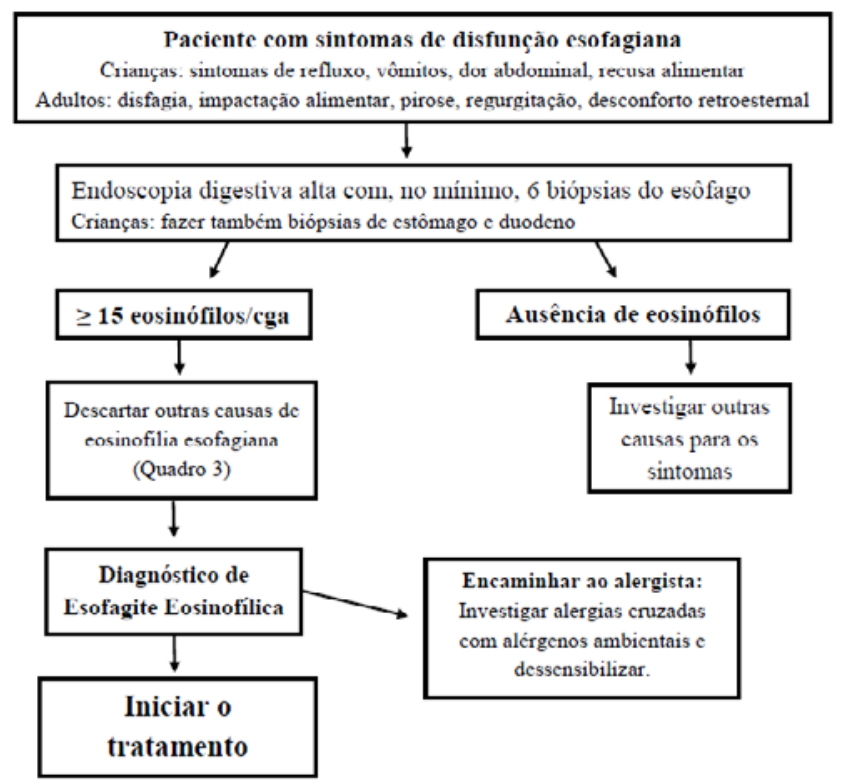

Figura 3: Proposta de algoritmo diagnóstico para Esofagite Eosinofilica. 
Tanto em adultos quanto em crianças, os objetivos do tratamento da Esofagite Eosinofílica são ${ }^{31}$ :

- Alívio dos sintomas;

- Preservaçáo do estado nutricional;

- Redução da atividade inflamatória no esôfago;

- Prevençáo do remodelamento, evitando ou retardando a fibroestenose.

Não há definiçôes ou estratificações bem estabelecidas de remissão sintomática, endoscópica ou histopatológica, o que dificulta estabelecer critérios de sucesso ou falha no tratamento.

Atualmente o que se busca é a completa resolução dos sintomas e uma contagem de eosinófilos abaixo de 15 por campo de grande aumento ${ }^{31}$, com a ressalva de que melhora clínica e resposta histopatológica nem sempre andam juntas.

Recentemente, um novo escore de atividade histopatológica foi proposto e validado $^{32}$, o que pode se tornar uma ferramenta útil no manejo terapêutico dessa doença, mas sua reprodutibilidade e seu valor prognóstico ainda precisam ser melhor avaliados.

Além disso, a melhora ou resoluçáo dos achados endoscópicos, quantificados pela classificação EREFS ${ }^{26}$, têm se mostrado uma ferramenta cada vez mais útil e objetiva na avaliação da atividade inflamatória.

Para alcançar os objetivos acima, tanto o diagnóstico quanto o tratamento deveriam ocorrer o mais precocemente possível, para que o paciente tenha mais benefícios em longo prazo. Mesmo para aqueles diagnosticados já na fase fibroestenótica, o alívio dos sintomas e a redução da atividade inflamatória devem ser buscados.

Outro conceito importante, à luz do conhecimento atual, é de que a terapia de manutenção deve ser contínua ${ }^{31}$. A suspensão do tratamento, mesmo após remissão completa da atividade inflamatória, está associada a recorrência dos sintomas e retorno da eosinofilia esofagiana ${ }^{1}$.

As opçóes de tratamento bem estabelecidas na literatura são: a dieta restritiva, os inibidores da bomba de prótons, os corticoides tópicos e a dilatação de esôfago.

\section{Dieta Restritiva}

A dieta foi a primeira abordagem terapêutica estudada. Ao ofertar dieta elementar à base de uma fórmula de aminoácidos a crianças com sintomas refratários a IBP, até entâo atribuídos à DRGE, observou-se expressiva melhora tanto nos sintomas quanto na eosinofilia esofagiana ${ }^{8}$. O princípio desse tratamento é reduzir a exposição de antígenos alimentares ao esôfago, interrompendo a resposta imunológica.

Estudos posteriores confirmaram a eficácia da fórmula de aminoácidos, com mais de $90 \%$ de remissão histológica em crianças ${ }^{33}$ e cerca de $75 \%$ de remissão em adultos ${ }^{34}$. 
Porém é bastante difícil de se instituir na prática, já que tem um sabor impalatável e requer a infusão através de uma sonda nasoenteral ${ }^{2}$. Hoje em dia seu uso estaria restrito como terapia de resgate em casos de refratariedade clínica, não sendo factível como terapia de manutenção em longo prazo.

Dadas as dificuldades da dieta elementar, outras modalidades de dieta empírica foram propostas, seguindo o mesmo racional de diminuir o estímulo antigênico alimentar ao esôfago. São elas: Dieta restritiva guiada por testes alérgicos, Dieta restritiva dos 6 alimentos, 4 alimentos ou 2 alimentos.

\section{Dieta Restritiva Guiada por Testes Alérgicos}

Essa dieta se baseia na identificação dos potenciais alimentos deflagradores da EoE através de testes alérgicos cutâneos. A grande limitação é que esses testes foram desenvolvidos para identificar reaçóes alérgicas mediadas por IgE, enquantoaEsofagiteEosinofílica parece ser mediada por complexas vias da imunidade celular, envolvendo os Linfócitos T helper 2 e diversos sinalizadores celulares.

Dessa forma, testes baseados em IgE podem ser muito úteis para identificar alergias cruzadas, potenciais riscos de anafilaxia, porém não devem identificar adequadamente os antígenos deflagradores da $\mathrm{EoE}^{35}$. O valor preditivo positivo (VPP) desses testes em adultos é de no máximo $44 \%{ }^{33}$.
Por outro lado, em crianças os testes alérgicos mostraram-se úteis, especialmente ao detectar alergia cruzada. Crianças com hipersensibilidade a determinados antígenos pelos testes baseados em IgE apresentamse com doença histológica mais grave no esôfago e mais chance de remodelamento, estando indicada a dessensibilização ${ }^{36}$. Esta forma tem relação com a expressão do gene promotor TGFbeta1.

\section{Dieta Restritiva dos Seis, Quatro ou Dois Alimentos}

Esta é uma dieta empírica na qual se propóe retirar do consumo seis grupos de alimentos considerados altamente alergênicos: 1) Leite de vaca, 2) Ovos, 3) Soja, 4) Trigo, 5) Nozes/amendoim/castanhas e 6) Peixes/frutos do mar $^{37}$. Após 6 a 8 semanas de dieta, uma nova endoscopia com biópsias deve ser realizada para avaliar a remissão histológica ${ }^{5,31}$. Estudos sugerem altas taxas de remissão, superando $70 \%$ tanto em crianças quanto em adultos ${ }^{1,37}$.

A reintrodução alimentar deve ser feita em etapas. Recomenda-se a realização de nova endoscopia com biópsias do esôfago após a reintrodução de cada 1 ou 2 alimentos, na tentativa de identificar aquele que seja mais antigênico para o paciente, podendose liberar o consumo dos demais. Não há definição entre o intervalo para realização das endoscopias após a reintrodução alimentar ${ }^{5}$. 
Por ser um processo bastante trabalhoso, oneroso e invasivo, pesquisadores propuseram reduzir essa dieta para quatro alimentos: 1) Leite de vaca, 2) Trigo, 3) ovos e 4) Soja ${ }^{37}$. Há ainda a proposta de se reduzir para 2 alimentos, que foram identificados como sendo deflagradores em mais de $80 \%$ dos casos, são eles: 1) Leite de vaca e 2) Trigo.

Em publicação recente, o pesquisador Molina-Infante sugeriu o que chamou de estratégia "step-up 2-4-6". Consiste numa inversão da dieta dos 6 alimentos: inicia-se com a suspensão apenas dos 2 principais deflagradores (leite e trigo), com posterior avaliação histológica do esôfago. Caso a remissão não tenha sido alcançada, avançase para 4 elementos (leite, trigo, ovos, soja) e posteriormente para os 6 alimentos. Essa estratégia tende a reduzir significativamente o número de endoscopias digestivas ${ }^{37}$.

Não há estudos controlados comparando diretamente a dieta empírica com outras modalidades medicamentosas de tratamento. A opção por esse tratamento deve ser bastante discutida com o paciente e seus familiares, pois trata-se de uma dieta bastante restritiva, com alto custo financeiro e psicossocial, além de envolver a realização de diversas endoscopias. A grande vantagem de se identificar o(s) alimento(s) deflagrador(res) é a possibilidade de uma terapia de manutenção de longo prazo livre de medicaçóes ${ }^{1}$.

\section{Inibidores de Bomba de Prótons}

Por muito tempo, a resposta aos IBPs em pacientes com eosinofilia esofagiana era considerada como um marcador da Doença do Refluxo Gastroesofágico (DRGE). Hoje são considerados drogas de primeira linha no tratamento da Esofagite Eosinofílica. Isso porque agem como verdadeiros anti-inflamatórios diretamente na mucosa esofágica, inibindo a atividade dos linfócitos $\mathrm{Th}^{2}$ e a expressão da IL-3, reduzindo a quimiotaxia dos eosinófilos via Eotaxina-3. Além disso, a supressão do estímulo ácido no esôfago reduz o alargamento dos espaços intercelulares e diminui a exposição antigênica à camada subepitelial.

Pacientes com eosinofilia esofagiana que respondem aos IBPs são hoje incorporados ao escopo da Esofagite Eosinofílica e, possivelmente, representam um fenótipo dessa doença. A resposta ao tratamento com IBPs varia entre 30 e $70 \%{ }^{2}$. Essas drogas são recomendadas tanto para induzir remissáo quanto para manutenção em longo prazo ${ }^{1}$.

Para remissão, recomenda-se iniciar o tratamento com Omeprazol $40 \mathrm{mg}$ duas vezes ao dia (ou outro IBP em dose equivalente), com posterior avaliação histológica do esôfago em 8 semanas. Em crianças a dose é de $1-2 \mathrm{mg} / \mathrm{kg}$ de Omeprazol diariamente (ou equivalente). Alcançando-se remissão clínica, histológica e endoscópica, pode-se tentar a redução do IBP até a menor dose efetiva, ou seja, aquela capaz de manter o controle dos sintomas e da atividade inflamatória ${ }^{1,31}$. 
Não há definição do momento ideal para se tentar a redução da dose. Em um estudo prospectivo em adultos, o IBP em metade da dose inicial foi capaz de manter remissão cínica e histológica em $75 \%$ dos pacientes após 1 ano de acompanhamento ${ }^{38}$. Pacientes respondedores devem manter tratamento contínuo. Suspensóes, mesmo que temporárias da droga, associaram-se a recaída clínica e histológica ${ }^{31}$.

Aqueles pacientes que apresentarem recorrência, mesmo em uso contínuo da droga, podem ter sua dose novamente aumentada. A ausência de resposta em altas doses de IBP configura falência dessa opção terapêutica, devendo-se tentar outra modalidade de tratamento.

\section{Corticoides Tópicos Deglutidos}

Desde os primeiros estudos na década de 1990, os corticoides tópicos deglutidos foram considerados uma opção satisfatória no tratamento da Esofagite Eosinofílica ${ }^{10}$. Logo se observou que eles tinham a mesma efetividade da prednisona oral, porém com muito menos eventos adversos e melhor tolerabilidade $^{39}$.

Dessa forma, atualmente não há indicação para o uso rotineiro de corticoides sistêmicos nessa doença, pois não existe qualquer vantagem em relação aos corticoides tópicos. Seu uso está restrito a situaçóes de emergência, como na disfagia muito grave ou na perda de peso rápida e significativa ${ }^{31}$.

Fluticasona e Budesonida tópicas, em preparaçóes feitas para asma e rinite, são as drogas mais estudadas em ensaios clínicos controlados, mostrando efeitos semelhantes em induzir remissão, variando entre $73 \mathrm{e}$ $74,3 \%{ }^{31}$. Entretanto, preparaçóes com maior viscosidade seriam potencialmente melhores, ao recobrir uma maior área de contato do esôfago.

Nesse sentido, recentemente foi lançada e aprovada para uso na Europa uma formulação de Budesonida em tablete orodispersível (Jorveza $1 \mathrm{mg}$ ), droga esta que mostrou uma eficácia de quase $100 \%$ em alcançar remissão histológica após 2 a 6 semanas de uso ${ }^{40}$. Esta é a primeira formulação desenvolvida especificamente para o tratamento da Esofagite Eosinofílica. Não há previsão para aprovação e comercializaçáo desta droga no Brasil.

Estudos sobre o tratamento de manutençáo em longo prazo com corticoides tópicos são menos comuns. Porém prevalece a recomendação de que, uma vez tendo respondido a essas drogas, os pacientes devem manter $o$ uso contínuo para evitar recorrência ${ }^{1,5,31}$.

Até o momento, não se observou maior incidência de candidíase de esôfago em usuários crônicos dessas drogas e o potencial efeito de supressão da glândula suprarrenal ainda está em estudo ${ }^{31}$. Alguns centros de referência adotam como rotina a dosagem de cortisol e ACTH séricos, mesmo sem evidência formal que sustente essa conduta ${ }^{41}$. 
As doses recomendadas dos corticoides tópicos estão na Tabela 2:

\begin{tabular}{llll}
\hline Medicação & População & Dose para induzir remissão & Dose de manutenção \\
\hline & & (Dividida em 2 vezes ao dia) & (Dividida em 2 vezes ao dia) \\
\hline $\begin{array}{l}\text { Propionato de } \\
\text { Fluticasona }\end{array}$ & Crianças & $\begin{array}{l}880 \mathrm{a} 1760 \mathrm{mcg} / \mathrm{dia} \\
1760 \mathrm{mcg} / \mathrm{dia}\end{array}$ & $\begin{array}{l}440 \mathrm{a} 880 \mathrm{mcg} / \mathrm{dia} \\
880 \mathrm{a} 1760 \mathrm{mcg} / \mathrm{dia}\end{array}$ \\
\hline \multirow{2}{*}{ Budesonida } & Adultos & 1 a $2 \mathrm{mg} / \mathrm{dia}$ & $1 \mathrm{mg} / \mathrm{dia}$ \\
& Crianças & 2 a $4 \mathrm{mg} / \mathrm{dia}$ & $2 \mathrm{mg} / \mathrm{dia}$ \\
\hline
\end{tabular}

Adaptado de Lucendo e cols. (Material suplementar, tabela 6) 1 .

No Brasil, a Fluticasona está disponível em preparaçóes inaláveis de até $250 \mathrm{mcg}$ por dose. Para alcançar a equivalência das doses recomendadas, a posologia ficará assim:

\begin{tabular}{lll}
\hline Crianças & Remissão & 2 a 3 puffs duas vezes ao dia \\
& Manutenção & 1 a 2 puffs duas vezes ao dia \\
\hline Adultos & Remissão & 3 a 4 puffs duas vezes ao dia \\
& Manutenção & 2 a 3 puffs duas vezes ao dia \\
\hline
\end{tabular}

É preciso reforçar a orientação de que os puffs não devem ser inalados como está escrito na bula da medicação. Após a aspersão do conteúdo diretamente na cavidade oral, sem usar o espaçador, ele deve ser totalmente deglutido, mantendo-se um período de jejum (para sólidos e líquidos) nos próximos 30 a 60 minutos.

A Budesonida se mostrou mais efetiva em soluções viscosas. No Brasil, esta droga está disponível em suspensões para nebulização, em frascos de $2 \mathrm{ml}$ contendo $1 \mathrm{mg}$. Para preparar uma solução viscosa, recomenda-se misturar cada $2 \mathrm{ml}$ de Budesonida com $5 \mathrm{mg}$ de sucralose ou outro meio viscoso como o mel. A consistência final será semelhante a um xarope.

O controle endoscópico com biópsias deve ser realizado entre 8 a 12 semanas após o início do tratamento. O momento adequado para redução da dose não está bem definido $^{31}$, podendo ser tentada após a remissão dos sintomas e resposta histológica em 12 semanas.

\section{DilataÇấo do Esôfago}

A dilatação de esôfago é realizada através da endoscopia digestiva alta, utilizando-se velas dilatadoras ou balóes hidrostáticos, sendo considerada segura mesmo em pacientes com Esofagite Eosinofílica. O objetivo é manter o calibre do esôfago com pelo menos $16 \mathrm{~mm}$.

Apesar do temor inicial de que essa técnica tivesse maior incidência de perfuraçôes, as evidências não apontaram nesse sentido, reve- 
lando um risco de perfuração menor do que $1 \%{ }^{1}$. Dor retroesternal pode ocorrer em até $30 \%$ dos pacientes. Não houve diferença em relação ao dispositivo de dilatação utilizado ${ }^{1}$.

Está indicada em pacientes com estenose grave, mesmo como tratamento inicial, e também em pacientes que permanecem sintomáticos apesar do tratamento clínico. É capaz de aliviar a disfagia em mais de $75 \%$ dos pacientes e proporcionar longos períodos de alívio sintomático ${ }^{1}$, mas não causam melhora inflamatória ou histológica ${ }^{31}$.

Existem poucos dados disponíveis sobre a dilatação em crianças, sendo necessários mais estudos para avaliar a eficácia e segurança da técnica nessa população.

\section{Tratamentos Experimentais}

\begin{tabular}{|c|c|c|}
\hline Medicação & Mecanismo de ação & Evidência científica na EoE \\
\hline \multicolumn{3}{|l|}{ Imunomoduladores } \\
\hline $\begin{array}{l}\text { - Azatioprina } \\
\text { - 6-Mercaptopurina }\end{array}$ & Poupadores de corticoides & $\begin{array}{l}\text { Poucos relatos de casos referindo } \\
\text { remissão clínica e histológica. }\end{array}$ \\
\hline \multicolumn{3}{|l|}{ Antialérgicos: } \\
\hline - Cromoglicato & $\begin{array}{l}\text { Estabilizador de mastócitos } \\
\text { Inibidor de leucotrieno }\end{array}$ & $\begin{array}{l}\text { Ausência de resposta tanto clínica } \\
\text { quanto histológica. }\end{array}$ \\
\hline \multicolumn{3}{|l|}{ - Montelucaste } \\
\hline - Prostaglandina D2 & $\begin{array}{l}\text { Redução da cascata } \\
\text { inflamatória }\end{array}$ & $\begin{array}{l}\text { Relatos de casos com redução da } \\
\text { eosinofilia e sintomas, porém sem } \\
\text { normalização da mucosa. }\end{array}$ \\
\hline \multicolumn{3}{|l|}{ Agentes Biológicos } \\
\hline $\begin{array}{l}\text { - Infliximabe } \\
\text { - Omalizumabe } \\
\text { - Mepolizumabe } \\
\text { - Reslizumabe }\end{array}$ & $\begin{array}{l}\text { Anti-TNF alfa } \\
\text { Anti-lgE } \\
\text { Anti-IL5 } \\
\text { Anti-IL5 }\end{array}$ & $\begin{array}{l}\text { Em ensaios clínicos controlados, } \\
\text { não houve melhora sintomática ou } \\
\text { resposta histológica em comparação } \\
\text { ao placebo. }\end{array}$ \\
\hline
\end{tabular}

Com a evolução no conhecimento da etiopatogenia da EoE, vários medicamentos antialérgicos, imunomoduladores e biológicos (anticorpos monoclonais) vêm sendo testados nos últimos anos como alternativas terapêuticas. Eles agem em diferentes etapas da imunidade celular consideradas relevantes no mecanismo inflamatório da doença.

Os resultados, entretanto, têm sido bastante variáveis e inconsistentes. Atualmente, nenhuma dessas drogas pode ser indicada para uso rotineiro na Esofagite Eosinofílica. Algumas delas parecem promissoras, mas precisam de ensaios clínicos maiores para comprovar o benefício.

A Tabela 3 resume as principais medicaçôes em estudo, seus respectivos mecanismos de ação e o tipo de evidência científica já publicada: 
- Vedolizumabe

- QAX576

- RPC4046
Anti-Integrina

Anti-IL13
Relatos de caso com remissão histológica em poucos pacientes.

Estudo de fase II com melhora da contagem de eosinófilos, porém sem remissão inflamatória e sem melhora da disfagia.

Droga promissora: estudo de fase III mostrou melhora sintomática sustentada e resposta histológica na semana 52. Novos estudos são necessários.

Os conceitos fundamentais sobre o tratamento da Esofagite Eosinofílica estão resumidos no Quadro 4:

\section{Quadro 4: Resumo dos conceitos-chave no tratamento da Esofagite Eosinofilica}

- Não há estudos prospectivos, randomizados e controlados, comparando diretamente as três opções de tratamento: dieta, inibidores da bomba de prótons e corticoide tópico deglutido.

- $\quad$ Essas três opções são consideradas tratamentos de primeira linha, devendo ser discutidas questões como preferência individual, custo financeiro e psicossocial antes de decidir pela melhor modalidade terapêutica em cada caso.

- A duração do tratamento de manutenção não está definida. Mas, as evidências demonstraram que interrupções no tratamento, mesmo que temporárias, estão associadas a um alto risco de recorrência. Por isso, a recomendação atual é de que a terapia de manutenção seja contínua.

- Tanto o aumento da dose, quanto a troca ou combinação das modalidades terapêutica podem ser tentadas em pacientes de difícil tratamento.

- Corticoides sistêmicos não estão indicados de rotina, apenas em situações emergenciais, como na disfagia grave e/ou perda ponderal rápida e acentuada.

- $\quad$ Dieta elementar à base de fórmulas de aminoácidos tem eficácia superior a 90\%, devendo ser lembrada como terapia de resgate em casos refratários.

- A dilatação instrumental do esôfago pode ser feita desde a primeira abordagem do paciente com estenose grave, ou em decorrência de sintomas refratários ao tratamento clínico.

- Há poucas informações sobre eficácia e segurança da dilatação em crianças.

- Tratamentos experimentais são aceitáveis apenas em casos refratários a todas as outras modalidades terapêuticas bem estabelecidas. 
A Figura 4 propõe um algoritmo de tratamento para a Esofagite Eosinofílica:

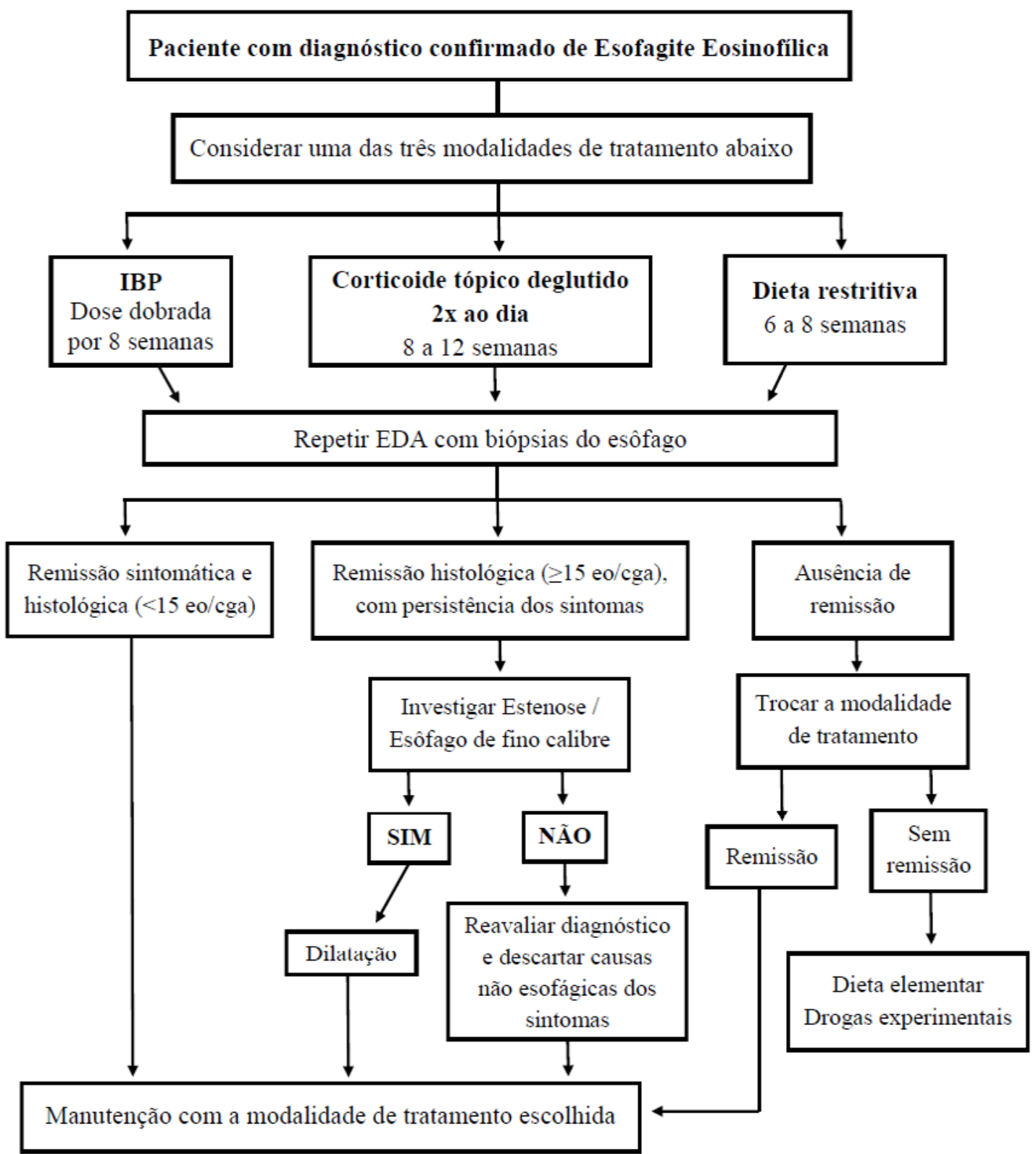

Figura 4: proposta de algoritmo de tratamento para a Esofagite Eosinofilica 


\section{REFERÊNCIAS BIBLIOGRÁFICAS}

1. Lucendo AJ, Molina-Infante J, Arias A, et al. Guidelines on eosinophilic esophagitis: evidence-based statements and recommendations for diagnosis and management in children and adults. United European Gastroenterol J 2017;5:335-358.

2. Dellon ES, Liacouras CA, MolinaInfante J, et al. Updated International Consensus Diagnostic Criteria for Eosinophilic Esophagitis: Proceedings of the AGREE Conference.

Gastroenterology 2018;155:10221033.e10.

3. Arias A, Lucendo AJ. Incidence and prevalence of eosinophilic oesophagitis increase continiously in adults and children in Central Spain: A 12-year population-based study. Dig Liver Dis 2019;51:55-62.

4. Warners MJ, Oude Nijhuis RAB, de Wijkerslooth LRH, et al. The natural course of eosinophilic esophagitis and long-term consequences of undiagnosed disease in a large cohort. Am J Gastroenterol 2018;113:836-844.

5. Gonsalves NP, Aceves SS. Diagnosis and treatment of eosinophilic esophagitis. J Allergy Clin Immunol 2020;145:1-7.

6. Winter HS, Madara JL, Stafford RJ, et al. Intraepithelial eosinophils: a new diagnostic criterion for reflux esophagitis. Gastroenterology 1982;83:818-23.

7. Attwood SE, Smyrk TC, Demeester TR, et al. Esophageal eosinophilia with dysphagia. A distinct clinicopathologic syndrome. Dig Dis Sci 1993;38:109-16.

8. Kelly KJ, Lazenby AJ, Rowe PC, et al. Eosinophilic esophagitis attributed to gastroesophageal reflux: improvement with an amino acid-based formula. Gastroenterology 1995;109:1503-12.

9. Furuta GT, Liacouras CA, Collins MH, et al. Eosinophilic esophagitis in children and adults: a systematic review and consensus recommendations for diagnosis and treatment. Gastroenterology 2007;133:1342-63.

10. Faubion WA, Jr., Perrault J, Burgart LJ, et al. Treatment of eosinophilic esophagitis with inhaled corticosteroids. J Pediatr Gastroenterol Nutr 1998;27:90-3.

11. Liacouras CA, Furuta GT, Hirano I, et al. Eosinophilic esophagitis: updated consensus recommendations for children and adults. J Allergy Clin Immunol 2011;128:3-20.e6; quiz 21-2.

12. Blanchard C, Wang N, Stringer $\mathrm{KF}$, et al. Eotaxin-3 and a uniquely conserved gene-expression profile in eosinophilic esophagitis. J Clin Invest 2006;116:536-47. 
13. Shoda T, Matsuda A, Nomura I, et al. Eosinophilic esophagitis versus proton pump inhibitor-responsive esophageal eosinophilia: Transcriptome analysis. J Allergy Clin Immunol 2017;139:2010-2013.e4.

14. Cheng E, Zhang X, Huo X, et al. Omeprazole blocks eotaxin-3 expression by oesophageal squamous cells from patients with eosinophilic oesophagitis and GORD. Gut 2013;62:824-32.

15. Min JY, Ocampo CJ, Stevens WW, et al. Proton pump inhibitors decrease eotaxin-3/CCL26 expression in patients with chronic rhinosinusitis with nasal polyps: Possible role of the nongastric H,K-ATPase. J Allergy Clin Immunol 2017;139:130-141.e11.

16. O'Shea KM, Aceves SS, Dellon ES, et al. Pathophysiology of Eosinophilic Esophagitis. Gastroenterology 2018;154:333-345.

17. Hirano I, Chan ES, Rank MA, et al. AGA institute and the joint task force on allergy-immunology practice parameters clinical guidelines for the management of eosinophilic esophagitis. Ann Allergy Asthma Immunol 2020;124:416-423.

18. Tobey NA, Hosseini SS, Argote CM, et al. Dilated intercellular spaces and shunt permeability in nonerosive aciddamaged esophageal epithelium. Am J Gastroenterol 2004;99:13-22.
19. Dunbar KB, Agoston AT, Odze RD, et al. Association of Acute Gastroesophageal Reflux Disease With Esophageal Histologic Changes. Jama 2016;315:2104-12.

20. Calabrese C, Bortolotti M, Fabbri A, et al. Reversibility of GERD ultrastructural alterations and relief of symptoms after omeprazole treatment. Am J Gastroenterol 2005;100:537-42.

21. Ram G, Lee J, Ott M, et al. Seasonal exacerbation of esophageal eosinophilia in children with eosinophilic esophagitis and allergic rhinitis. Ann Allergy Asthma Immunol 2015;115:224-228.e1.

22. Fox VL, Nurko S, Teitelbaum JE, et al. High-resolution EUS in children with eosinophilic "allergic" esophagitis. Gastrointest Endosc 2003;57:30-6.

23. Rajan J, Newbury RO, Anilkumar A, et al. Long-term assessment of esophageal remodeling in patients with pediatric eosinophilic esophagitis treated with topical corticosteroids. J Allergy Clin Immunol 2016;137:147-156.e8.

24. Schoepfer AM, Safroneeva E, Bussmann C, et al. Delay in diagnosis of eosinophilic esophagitis increases risk for stricture formation in a timedependent manner. Gastroenterology 2013;145:1230-6.e1-2.

25. Liacouras CA, Spergel JM, Ruchelli E, et al. Eosinophilic esophagitis: a 10- 
year experience in 381 children. Clin Gastroenterol Hepatol 2005;3:1198206.

26. Hirano I, Moy N, Heckman MG, et al. Endoscopic assessment of the oesophageal features of eosinophilic oesophagitis: validation of a novel classification and grading system. Gut 2013;62:489-95.

27. Wechsler JB, Bolton SM, Amsden $\mathrm{K}$, et al. Eosinophilic Esophagitis Reference Score Accurately Identifies Disease Activity and Treatment Effects in Children. Clin Gastroenterol Hepatol 2018;16:1056-1063.

28. Katzka DA, Geno DM, Ravi A, et al. Accuracy, safety, and tolerability of tissue collection by Cytosponge vs endoscopy for evaluation of eosinophilic esophagitis. Clin Gastroenterol Hepatol 2015;13:77-83. e2.

29. Menard-Katcher C, Benitez AJ, Pan Z, et al. Influence of Age and Eosinophilic Esophagitis on Esophageal Distensibility in a Pediatric Cohort. Am J Gastroenterol 2017;112:1466-1473.

30. Hassan M, Aceves S, Dohil R, et al. Esophageal Compliance Quantifies Epithelial Remodeling in Pediatric Patients With Eosinophilic Esophagitis. J Pediatr Gastroenterol Nutr 2019;68:559-565.
31. Lucendo AJ. Pharmacological treatments for eosinophilic esophagitis: current options and emerging therapies. Expert Rev Clin Immunol 2020:1-15.

32. Collins MH, Martin LJ, Alexander ES, et al. Newly developed and validated eosinophilic esophagitis histology scoring system and evidence that it outperforms peak eosinophil count for disease diagnosis and monitoring. Dis Esophagus 2017;30:1-8.

33. Arias A, Gonzalez-Cervera J, Tenias JM, et al. Efficacy of dietary interventions for inducing histologic remission in patients with eosinophilic esophagitis: a systematic review and meta-analysis. Gastroenterology 2014;146:1639-48.

34. Peterson KA, Byrne KR, Vinson LA, et al. Elemental diet induces histologic response in adult eosinophilic esophagitis. Am J Gastroenterol 2013;108:759-66.

35. Rodriguez-Sanchez J, Gomez Torrijos E, Lopez Viedma B, et al. Efficacy of IgE-targeted vs empiric six-food elimination diets for adult eosinophilic oesophagitis. Allergy 2014;69:936-42.

36. Rawson R, Anilkumar A, Newbury RO, et al. The TGFbeta1 Promoter SNP C-509T and Food Sensitization Promote Esophageal Remodeling in 
Pediatric Eosinophilic Esophagitis.

PLoS One 2015;10:e0144651.

37. Molina-Infante J, Lucendo AJ. Dietary therapy for eosinophilic esophagitis. J

Allergy Clin Immunol 2018;142:41-47.

38. Molina-Infante J, Rodriguez-Sanchez

J, Martinek J, et al. Long-Term

Loss of Response in Proton Pump

Inhibitor-Responsive Esophageal

Eosinophilia Is Uncommon and

Influenced by CYP2C19 Genotype

and Rhinoconjunctivitis. Am J

Gastroenterol 2015;110:1567-75.

39. Schaefer ET, Fitzgerald JF, Molleston

JP, et al. Comparison of oral

prednisone and topical fluticasone

in the treatment of eosinophilic

esophagitis: a randomized trial in

children. Clin Gastroenterol Hepatol

2008;6:165-73.

40. Lucendo AJ, Miehlke S, Schlag

C, et al. Efficacy of Budesonide

Orodispersible Tablets as Induction

Therapy for Eosinophilic Esophagitis

in a Randomized Placebo-Controlled

Trial. Gastroenterology 2019;157:74-

86.e15.

41. Hirano I. How I Approach the

Management of Eosinophilic

Esophagitis in Adults. Am J

Gastroenterol 2017;112:197-199. 